\title{
O cinturão epidérmico de antepaís da Bacia de Irecê, Cráton do São Francisco: principais elementos estruturais e modelagem física analógica
} The thin-skinned fold-and-thrust belt of Irecê Basin, São Francisco Craton: main structural setting and physical analog modeling

\author{
Humberto Luis Siqueira Reis', Caroline Janette Souza Gomes², \\ Daniel Galvão Carnier Fragoso ${ }^{3}$, Matheus Kuchenbecker ${ }^{4}$ \\ ${ }^{1}$ Petra Energia S. A., Alameda Oscar Niemeyer 119, $15^{\circ}$ andar, Vila da Serra, CEP 34000-000, \\ Nova Lima, MG, BR (humbertosiqueira@gmail.com) \\ ${ }^{2}$ Departamento de Geologia, Escola de Minas, Universidade Federal de Ouro Preto - UFOP, \\ Ouro Preto, MG, BR (caroline@degeo.ufop.br) \\ ${ }^{3}$ Escola de Ciências e Tecnologia de Exploração e Produção, Universidade Petrobras - PETROBRAS, \\ Rio de Janeiro, RJ, BR (danielfragoso@petrobras.com.br) \\ ${ }^{4}$ Centro de Pesquisa Professor Manoel Teixeira da Costa, Instituto de Geociências, Universidade Federal de Minas Gerais - UFMG, \\ Belo Horizonte, MG, BR (mk.geologia@gmail.com)
}

Recebido em 01 de abril de 2013; aceito em 12 de setembro de 2013

\begin{abstract}
Resumo
Localizada na porção central do estado da Bahia, a Bacia de Irecê exibe as mais significativas exposições de coberturas neoproterozoicas da porção norte do Cráton do São Francisco. Apesar da grande quantidade de estudos geológicos ali realizados, restam ainda várias questões em aberto, em especial no que tange à evolução tectônica do cinturão epidérmico de antepaís que envolve as rochas da bacia. No sentido de contribuir para o entendimento de tal evolução, este trabalho revisa os principais elementos estruturais da bacia e adjacências e apresenta novos dados adquiridos por meio de modelo físico-analógico em caixa de areia. O cinturão epidérmico de antepaís da Bacia de Irecê corresponde a uma grande feição curva confinada ao longo do sinclinal homônimo e tem sua formação atribuída ao fechamento das faixas marginais do setor norte do Cráton do São Francisco. Seu desenvolvimento foi condicionado por um vetor tectônico N-S, responsável pela nucleação de dobras e falhas E-W. Nas bordas da bacia, a deformação é acomodada através de falhas direcionais responsáveis pela rotação geral das estruturas. Para o sul, o cinturão perde gradativamente sua expressividade, ocorrendo apenas as estruturas geradas previamente durante o desenvolvimento do Sistema de Dobras e Empurrões da Chapada Diamantina. O modelo físico-analógico em caixa de areia simulou com sucesso o desenvolvimento do Cinturão de Antepaís da Bacia de Irecê e indica que sua curvatura em planta resulta da interação com as bordas do sinclinal e da própria curvatura do substrato. A propagação deu-se por meio de um descolamento com baixo coeficiente de atrito, provavelmente condicionado pelo contraste reológico entre as unidades carbonáticas do Grupo Una e o substrato quartzítico do Supergrupo Espinhaço.
\end{abstract}

Palavras-chave: Bacia de Irecê; Cinturão epidérmico de antepaís; Modelo físico-analógico em caixa de areia.

\begin{abstract}
Located in the central portion of Bahia state, Irecê Basin displays the best exposures of neoproterozoic sedimentary cover at Northern São Francisco Craton. Despite of the large amount of geological studies performed there, some questions remain unsolved, especially concerning the tectonic evolution of the thin-skinned fold-and-thrust belt that involves the rocks of the basin. In order to contribute to the understanding of such evolution, the present study reviews the main structural elements of the basin and surroundings, and present new data acquired through sandbox physical analog modeling. The Thin-skinned Fold-and-thrust Belt of Irecê Basin is a great curved feature, confined in the homonymous syncline, whose genesis is related to the development of orogenic belts north of São Francisco Craton. Its evolution was conditioned by a N-S tectonic vector, responsible by the nucleation of E-W folds and thrusts. At basin boundaries, the deformation is accommodated by strike-slip faults, which locally rotated early structures. Towards south, the belt gradually loses its expression, only remaining structures related to the Chapada Diamantina thrust-and-fold system. The sandbox analog
\end{abstract}


model successfully simulated the development of the Thin-skinned Fold-and-thrust Belt of Irecê Basin, and indicates that its mapview curve results from the interaction with the syncline borders, as well as substrate geometry of the foreland belt. The propagation was made through a low-friction detachment, probably conditioned by the rheological contrast between the Una Group carbonates and the underlying Espinhaço Supergroup siliciclastic rocks.

Keywords: Irecê Basin; Thin-skinned fold-and-thrust belt; Sandbox physical analog modeling.

\section{INTRODUÇÃO}

Localizada no setor central do estado da Bahia (Chapada Diamantina), a Bacia de Irecê abrange uma área aproximada de $30.000 \mathrm{~km}^{2}$ e exibe as mais significativas exposições de coberturas neoproterozoicas conhecidas na porção norte do Cráton do São Francisco (Figura 1).

Alvo de importantes estudos geológicos desde meados do século XX (e.g.: Brito Neves, 1967; Inda e Barbosa, 1978; Bomfim et al., 1985; Pedreira et al., 1987; Lagoeiro, 1990; Dominguez, 1993; Rocha e Dominguez, 1993; Souza et al., 1993; Barbosa e Dominguez, 1996), a bacia continua despertando a atenção de diversos pesquisadores, especialmente no que tange ao seu acervo tectônico e estratigráfico. Dentre os elementos tectônicos, destaca-se a expressiva estruturação E-W dos sedimentos do Grupo Una, ali envolvidos em um cinturão epidérmico de antepaís com vergência geral para sul (Lagoeiro, 1990). Tal cinturão ocorre confinado em uma grande estrutura sinclinal de orientação NNW-SSE e, à primeira vista, em nítido contraste com os principais elementos tectônicos de orientação similar reconhecíveis ao longo de toda Chapada Diamantina e adjacências (Danderfer Filho, 1990; Alkmim et al., 1993; Pedreira, 1994).

Apesar dos diversos estudos, uma série de questionamentos ainda persiste quanto à evolução estrutural desse cinturão epidérmico de antepaís. Grande parte das questões refere-se aos diferentes conjuntos de estruturas observadas e sua relação com os principais eventos tectônicos que atingiram o setor norte do Cráton do São Francisco durante o Pré-cambriano. Conforme evolução proposta por Lagoeiro (1990) e Danderfer Filho (1990), as sucessões neoproterozoicas na bacia registram duas fases deformacionais distintas e de polaridade aproximadamente ortogonal. Tais fases relacionam-se a eventos orogenéticos diacrônicos e relacionados ao Ciclo Brasiliano, que foram responsáveis pela sua geometria e estruturação peculiares. Marcando a fase de deformação mais tardia, o cinturão epidérmico vergente para sul teria se desenvolvido em um contexto confinado, lateralmente influenciado por estruturas regionais desenvolvidas em tectonismo pretérito. Apesar de tais relações serem observáveis em escala regional, levantamentos de detalhe ao longo da porção central da bacia mostram persistentes estruturas de interferência, por vezes, sugerindo evolução diferenciada e um pouco mais complexa para o cinturão (Souza et al., 1993; Fragoso et al., 2008; Kuchenbecker et al., 2011).
Buscando-se um melhor entendimento do cinturão epidérmico de antepaís que envolve os depósitos neoproterozoicos da Bacia de Irecê, são revisados a seguir os principais elementos estruturais observados ao longo da bacia e adjacências. Posteriormente, apresentamos novos dados adquiridos por meio de modelo físico-analógico em caixa de areia, com os quais, a seguir, discutimos a estruturação do cinturão neoproterozoico à luz da evolução geotectônica do Cráton do São Francisco setentrional e faixas dobradas adjacentes.

\section{CONTEXTUALIZAÇÃO GEOLÓGICA}

A Bacia de Irecê insere-se na porção norte do Cráton do São Francisco, setor oriental do Aulacógeno Paramirim (Cruz e Alkmim, 2006). Nessa área, os sedimentos pré-cambrianos do Supergrupo Espinhaço e do Grupo Una assentam-se discordantemente sobre o embasamento arqueano/paleoproterozoico, cujas principais exposições são restritas às porções noroeste e sudoeste da região (Figura 1).

O Supergrupo Espinhaço, paleo-mesoproterozoico, constitui o principal substrato geológico da Bacia de Irecê e é composto por uma sucessão predominantemente siliciclástica com espessura superior a $2.000 \mathrm{~m}$. Conforme Pedreira (1994) e Pedreira e De Waele (2008), na região da Chapada Diamantina tais unidades integram quatro grandes sequências deposicionais, sedimentadas em um sistema do tipo rift-sag.

O Grupo Una, de idade neoproterozoica, assenta-se diretamente sobre os sedimentos do Supergrupo Espinhaço através de uma pronunciada discordância erosiva. Corresponde à principal unidade aflorante ao longo da Bacia de Irecê e é composto pelas formações Bebedouro e Salitre.

A Formação Bebedouro encerra uma sucessão de diamictitos, pelitos e arenitos depositados sob influência glacial (Guimarães, 1996; Figueiredo, 2008). A unidade ocorre em superfície de maneira localizada e descontínua, restrita às bordas da bacia e com espessura máxima em torno de $200 \mathrm{~m}$.

Recobrindo os sedimentos glaciogênicos da Formação Bebedouro, a Formação Salitre aflora ao longo de toda a Bacia de Irecê e constitui uma espessa sucessão carbonática plataformal, localmente dolomitizada e com raras ocorrências terrígenas. Conforme Souza et al. (1993), tal sucessão define dois grandes ciclos regressivo-transgressivos e 


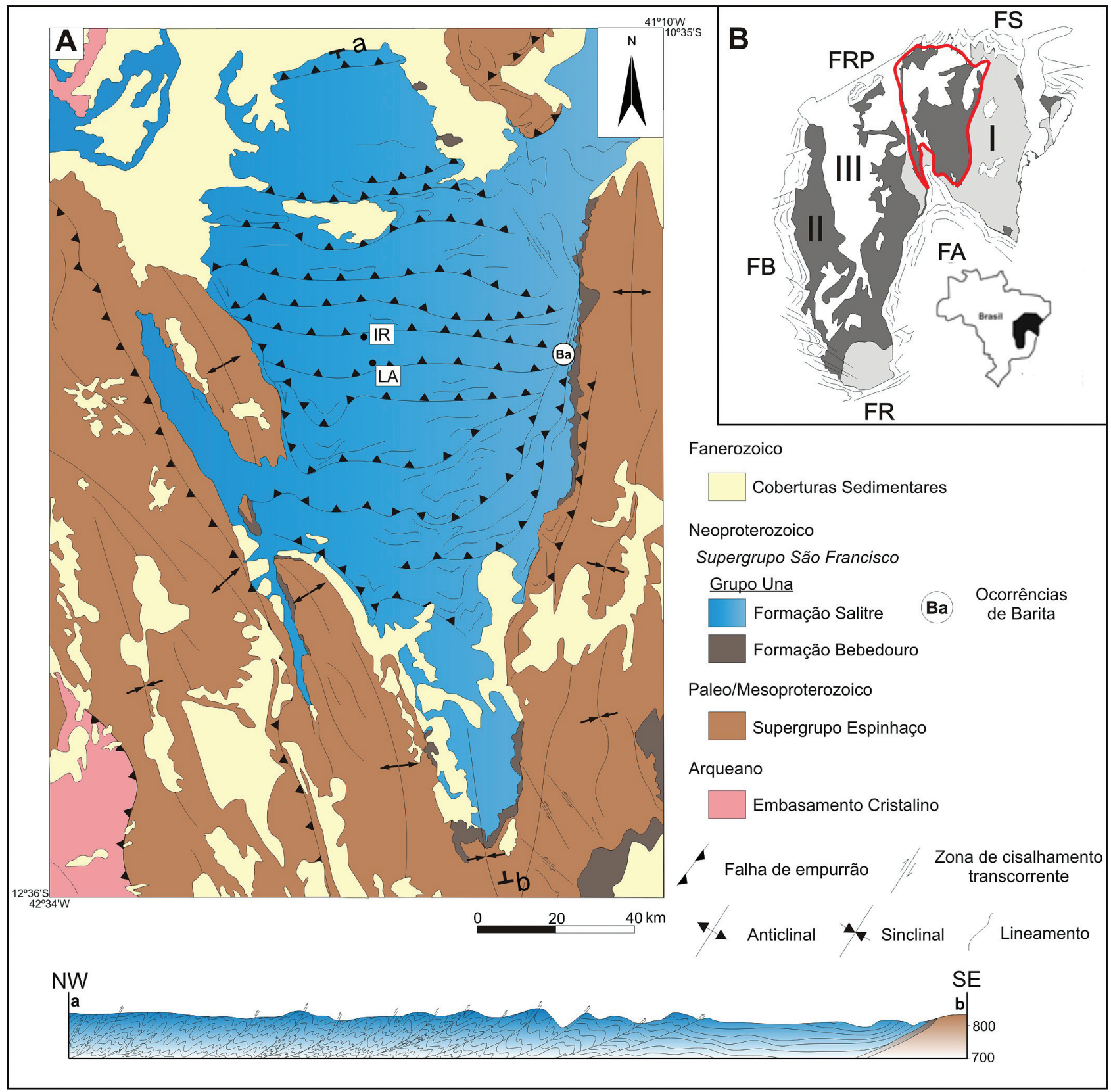

IR: Irecê; LA: Lapão.

I - Embasamento (> 1,8 Ga); II - Unidades Pré-Cambrianas; III - Cobertura Fanerozoica; FA: Faixa Araçuaí; FR: Faixa Ribeira; FB: Faixa Brasília; FRP: Faixas Rio Preto e Riacho do Pontal; FS: Faixa Sergipana. A linha vermelha destaca os limites do Aulacógeno Paramirim.

Figura 1. (A) Mapa e perfil geológicos simplificados da Bacia de Irecê e adjacências. Modificado de Kuchenbecker et al. (2011), Dalton de Souza et al. (2003), Lagoeiro (1990) e Danderfer Filho (1990). (B) Cráton do São Francisco e faixas marginais (Alkmim, 2004).

é composta por calcilutitos, calcarenitos e calcirruditos que, localmente, se associam a estromatólitos fosfáticos, ritmitos pelito-carbonáticos, camadas de chert e unidades sulfatadas. Estas últimas representam importantes ocorrências de barita, conhecidas, sobretudo, na borda leste da bacia e hospedadas em unidades contendo pseudomorfos nodulares de gipsita (Souza et al., 1993).
Sob o ponto de vista estrutural, as coberturas pré-cambrianas ao longo de todo Aulacógeno Paramirim encontram-se envolvidas em dois sistemas deformacionais distintos e diacrônicos (Danderfer Filho, 1990; Danderfer Filho et al., 1993; Lagoeiro, 1990). O primeiro, denominado Sistema de Dobramentos e Empurrões da Chapada Diamantina (Danderfer Filho, 1990), envolve tanto as 
coberturas do Supergrupo Espinhaço quanto os depósitos do Grupo Una. Corresponde a um cinturão deformacional de caráter embrionário, onde predominam dobramentos regionais com eixos preferencialmente orientados segundo a direção NNW-SSE e vergência geral para ENE. Esses dobramentos muitas vezes contêm mesoestruturas sistematicamente associadas às frequentes zonas de cisalhamento interestratais, principais responsáveis pela acomodação da deformação (Figura 2). Marcando um aumento deformacional progressivo, a oeste tais elementos são balizados por falhas de empurrão com orientação similar e vergentes para
ENE, que, por vezes, envolvem as rochas do embasamento. Essas descontinuidades ocorrem associadas ao desenvolvimento de foliação tectônica e à intensificação do metamorfismo no setor ocidental do Aulacógeno Paramirim, onde teriam evoluído a partir da inversão positiva de falhas normais paleo/mesoproterozoicas (Danderfer Filho et al., 1993).

O segundo sistema deformacional é representado por um cinturão epidérmico de antepaís com vergência geral para sul. Tal cinturão ocorre confinado à porção interna da Bacia de Irecê e envolve, predominantemente, as sucessões carbonáticas neoproterozoicas do Grupo Una.

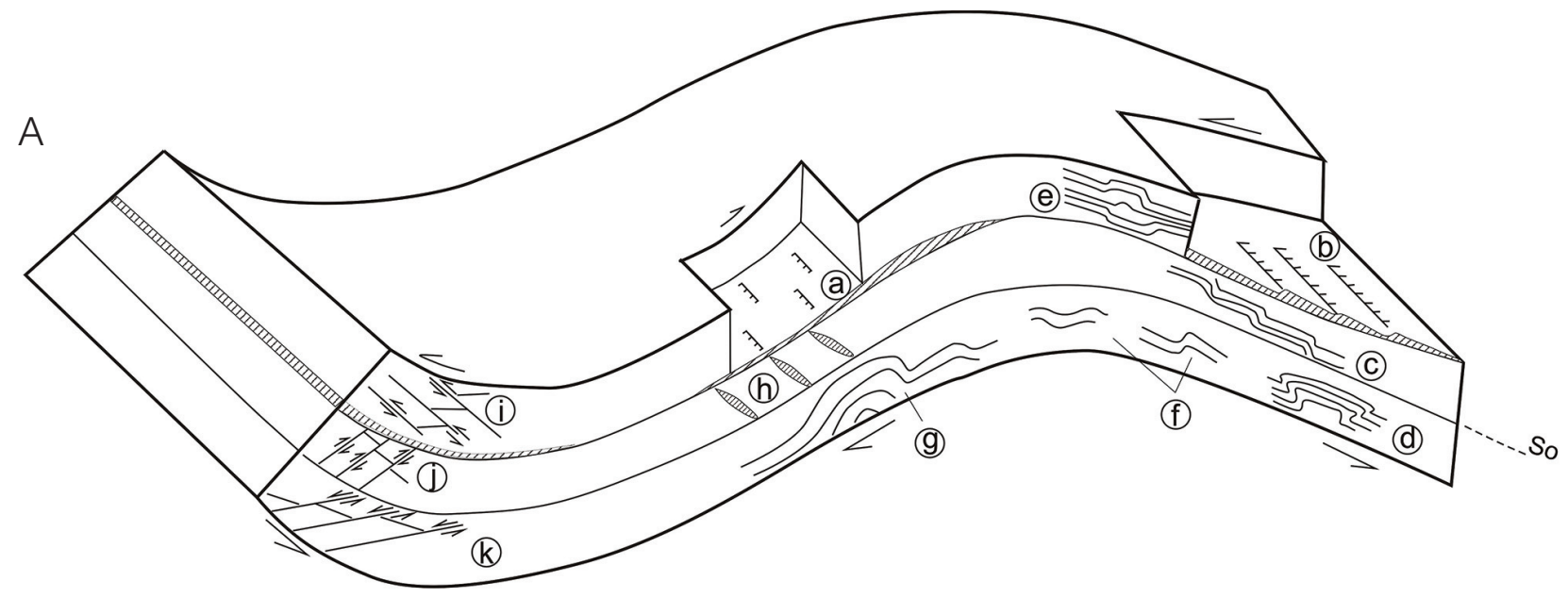
(a) Horizontes de movimento $(\mathrm{hm})$
(C) Kinks
(e) Kinks conjugados simétricos
(g) Fault-propagation-fold
(b) Estrias (Le), com degraus associados
(d) Kinks conjugados reversos
(f) Dobras de acomodação
(h) Tension gashes

\section{Fraturas}

(i) Tipo P (Sintética) (1) Tipo R' (Antitética) (B) Tipo R (Sintética)

\section{B}

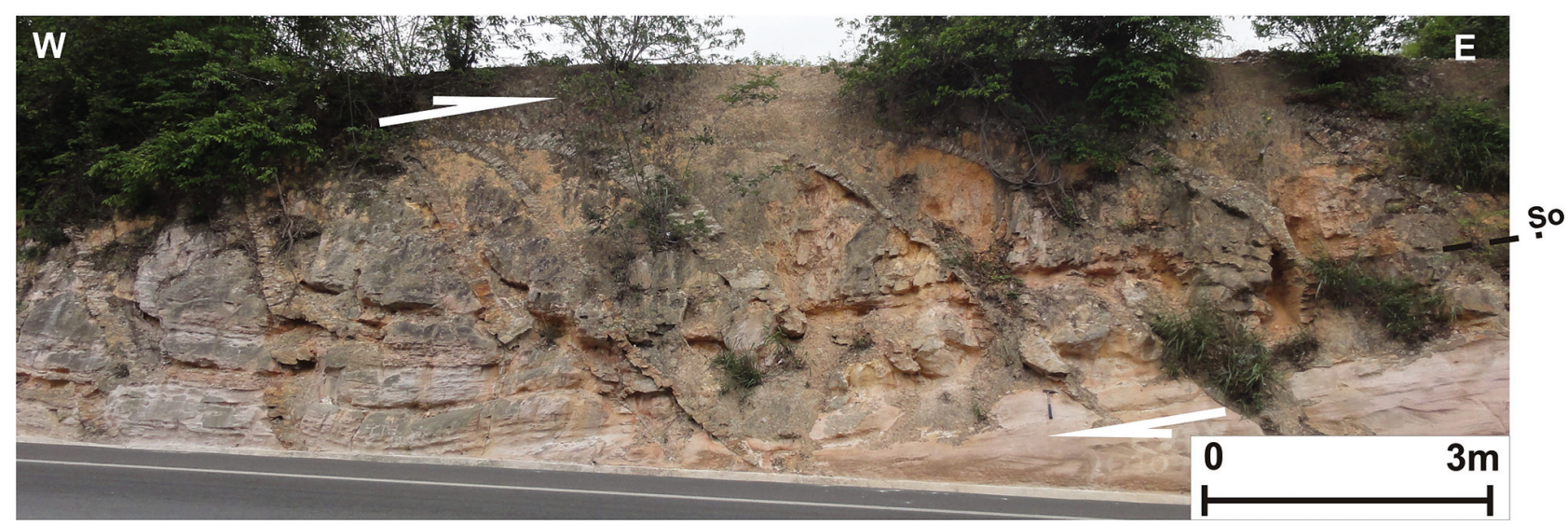

Figura 2. (A) Figura sinóptica mostrando as principais mesoestruturas associadas aos grandes sistemas de dobras regionais de eixo NNW-SSE (modificado de Danderfer Filho, 1990). (B) Foto de tension gashes (h, na Figura $2 \mathrm{~A}$ ) métricos em arenitos eólicos do Supergrupo Espinhaço no flaco oeste do Anticlinal de Seabra, SW da Bacia de Irecê (afloramento na BR242, próximo a Seabra-BA). As fendas indicam cisalhamento interestratal com movimentação de topo para leste. 


\section{O CINTURÃO EPIDÉRMICO DA BACIA DE IRECÊ}

O cinturão epidérmico de antepaís da Bacia de Irecê relaciona-se a um evento tectônico tardio durante o Ciclo Brasiliano, que superpõe os elementos estruturais do Sistema de Dobramentos e Empurrões da Chapada Diamantina. O mesmo envolve as rochas neoproterozoicas do Grupo Una em um sistema do tipo leque imbricado com vergência geral para S (Figuras 1 e 3). Tal feição restringe-se à porção norte do Aulacógeno do Paramirim e ocorre confinada ao longo de uma grande calha sinclinal de eixo NNW-SSE, denominada Bacia de Irecê (s.l.) (Lagoeiro, 1990).

Nesse setor do Cráton do São Francisco, os carbonatos da Formação Salitre encontram-se estruturados segundo um conjunto de falhas e dobras com traços curvilíneos e orientação geral E-W (Figuras 1 e 3). Tal conjunto define uma grande saliência de concavidade voltada para norte e é articulado em descolamento próximo à base da sucessão carbonática (Lagoeiro, 1990; Ribeiro, 2001; Cruz e Alkmim, 2006). Uma análise rápida das estruturas em planta permite observar que o ápice dessa saliência ocorre levemente deslocado para oeste, provavelmente relacionado à zona axial da Bacia de Irecê (Figura 3).

Conforme Lagoeiro (1990), na porção central do cinturão, predominam dobras em chevron com charneiras E-W e duplo caimento, que podem ocorrer em diversas escalas sendo, por vezes, balizadas por falhas de orientação similar e mergulho para norte. Nesse setor, são comuns estruturas de interferência de dobra, cujos eixos são aproximadamente ortogonais e definem, por vezes, figuras do tipo "domos e bacias" (Souza et al., 1993).

Em direção aos domínios leste e oeste do Sinclinal de Irecê, essas estruturas assumem traços de orientação NNE-SSW e NW-SE, respectivamente, e são acompanhadas pelo desenvolvimento de zonas de cisalhamento rúpteis direcionais de orientação similar. Essas zonas envolvem tanto os depósitos do Grupo Una quanto os litotipos do Supergrupo Espinhaço e são responsáveis pela extrusão das sucessões carbonáticas, bem como pela acomodação lateral do cinturão epidérmico ao longo das bordas da Bacia de Irecê.

No extremo sul da Bacia de Irecê, o cinturão epidérmico perde a expressão, permitindo a preservação dos elementos estruturais mais antigos. Nesse setor, predominam dobras com eixo de direção NNE-SSE e faturamento generalizado NW-SE e N-S.

\section{Arcabouço estrutural da porção central da Bacia de Irecê}

Com base em mapeamento geológico criterioso, Fragoso et al. (2008) reconhecem um padrão deformacional heterogêneo para a região central da Bacia de Irecê. Nessa região, porções intensamente deformadas são entremeadas por amplos setores onde a deformação é desprezível ou inexistente. A principal

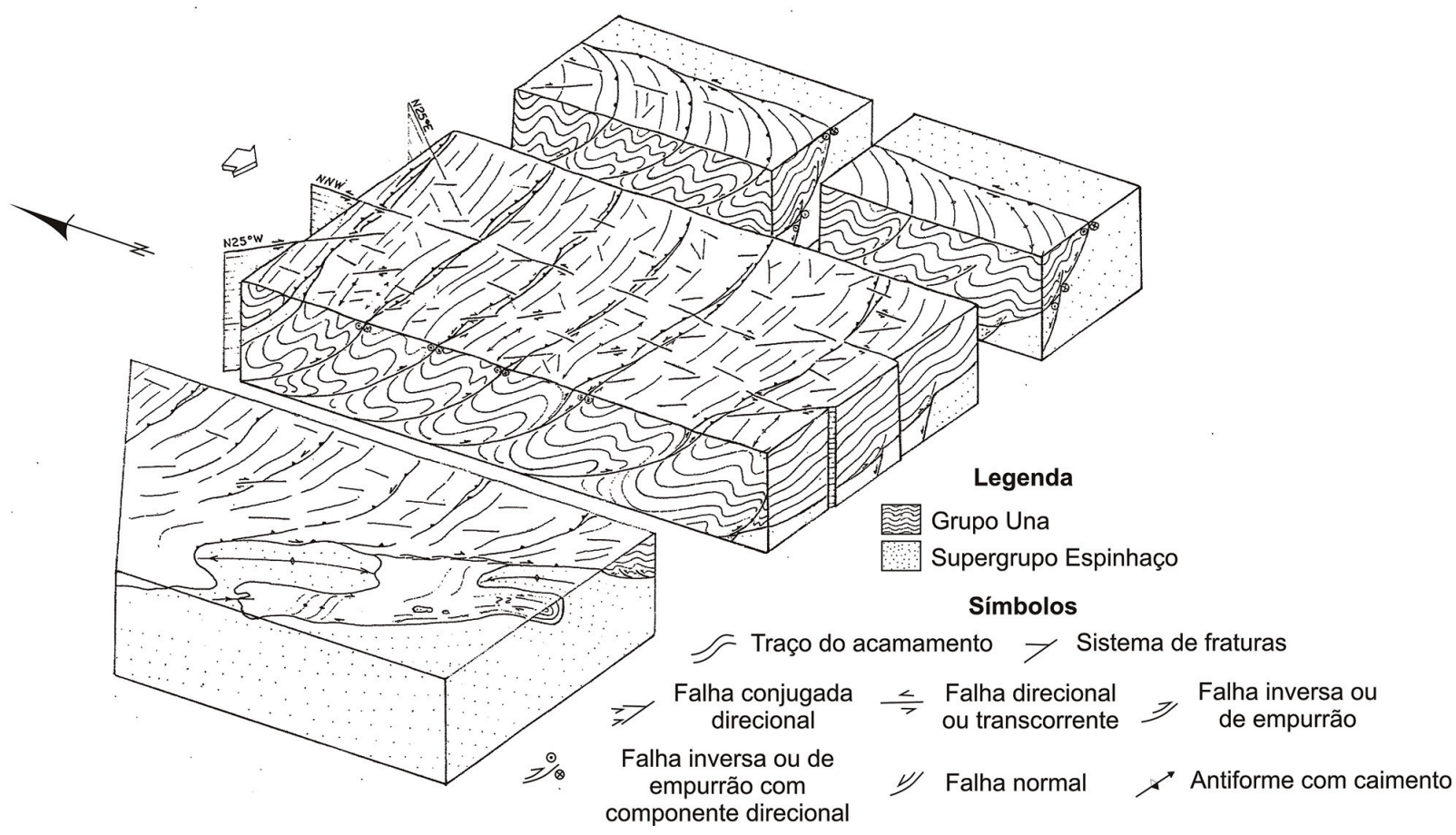

Figura 3. Modelo tridimensional esquemático idealizado por Lagoeiro (1990) para o cinturão de antepaís da Bacia de Irecê. 
feição estrutural observada corresponde a um sistema de mesodobras normais em chevron, acilíndricas, sem vergência definida, apertadas e com eixos sub-horizontais orientados segundo a direção E-W. Tais estruturas associam-se, localmente, a uma foliação plano-axial pouco desenvolvida, bem como a falhas de empurrão vergentes para sul (Figura 4).

Nesse setor da bacia, a disposição geral das principais fraturas, bem como os sistemas de tension gashes conjugados, quando relacionados às estruturas descritas anteriormente, definem um $\sigma 1$ orientado segundo a direção NNESSW e $\sigma 3$ conforme a direção WNW-ESE (Figura 5).

Uma geração mais tardia de dobras, com eixos orientados em torno da direção N-S e de menor magnitude, superpõe as estruturas anteriores e é comumente observada ao longo de toda área.
Quando analisadas sob a perspectiva regional, as principais estruturas observadas na porção central da bacia refletem a edificação do cinturão epidérmico da Bacia de Irecê, cujo transporte tectônico deu-se aproximadamente para SSW. Nesse contexto, o predomínio de dobras sem vergência definida em detrimento das falhas parece refletir um descolamento relativamente dúctil. Conforme observado em modelos físico-analógicos realizados por diversos autores (e.g.: Huiqi et al., 1992; Ribeiro, 2001; Lujan et al., 2003), o estilo estrutural observado em cinturões compressivos está comumente relacionado ao caráter friccional de seu descolamento basal. Segundo Fragoso et al. (2008) e Kuchenbecker et al. (2011), a geração mais tardia de dobras poderia ser resultado do confinamento do cinturão e sua interação com as bordas da bacia.
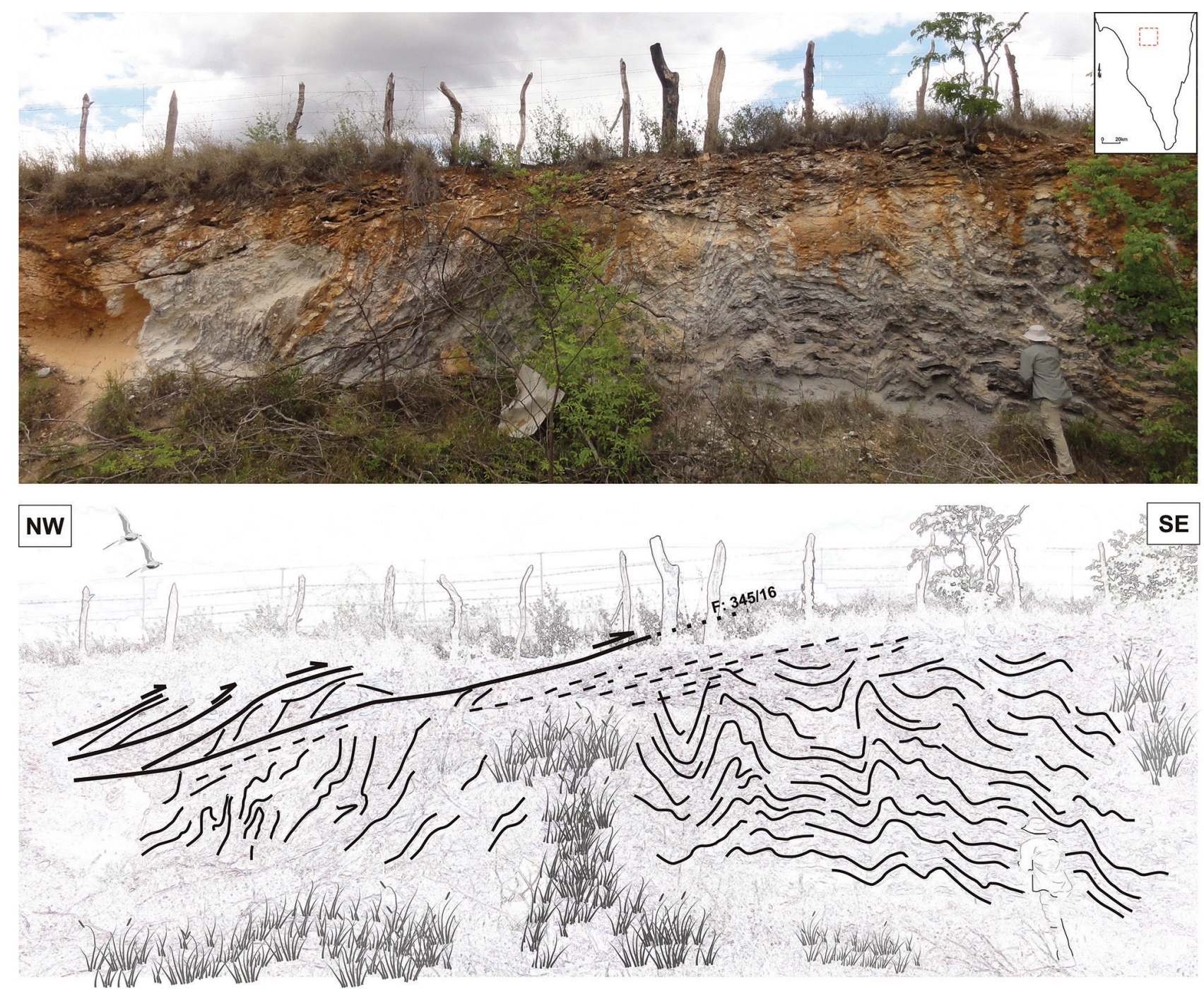

Figura 4. Zona de falha nas proximidades de São Gabriel (BA), setor central da Bacia de Irecê. Notar o a ocorrência de dobras desarmônicas e o desenvolvimento de planos de foliação (linhas tracejadas) associados às falhas. Nessa área, os calcilutitos da Unidade Irecê (Formação Salitre) são envolvidos em pequenas estruturas do tipo duplex vergentes para sul. 


\section{MODELAGEM TECTÔNICA}

\section{Materiais}

No experimento foi utilizada areia de quartzo seca tingida com tinta de tecido Acrilex, de granulometria $\leq 200 \mu \mathrm{m}$ e ângulo de atrito interno entre 37,9 e $45,5^{\circ}$. A mesma foi acomodada sobre uma camada de $0,3 \mathrm{~cm}$ de silicone incolor (SGM 36 PDMS, produzida pela Dow Corning), de comportamento newtoniano e viscosidade igual a $1,77 \mathrm{x}$ $10^{4} \mathrm{~Pa}$.s, a $20^{\circ} \mathrm{C}$. A camada de areia, de ca. $0,9 \mathrm{~cm}$, simulou as coberturas carbonáticas do Grupo Una e o silicone, o descolamento regional de baixa fricção. Utilizou-se uma caixa de acrílico com espaço interno de 60 × $30 \mathrm{~cm}$ (comprimento x largura), dotada de uma parede móvel (Figura 6) e acoplada a um motor capaz de gerar uma compressão à taxa de $3 \mathrm{~cm} / \mathrm{h}$.

\section{Escala}

O modelo analógico foi montado conforme os princípios de similaridade geométrica, cinemática e dinâmica propostos por Hubbert (1937) e Ramberg (1981). A Tabela 1 apresenta os parâmetros de escala adotados.

Pelo princípio da similaridade dinâmica (Hubbert, $1937)$, a razão das tensões coesivas entre o modelo $(\sigma \mathrm{mod})$ e a natureza ( $\sigma$ nat) pode ser calculada pela Equação 1:

$\sigma^{*}=\frac{\sigma_{\text {mod }}}{\sigma_{\text {nat }}}=L^{*} \cdot p^{*} \cdot g^{*}$

onde $L^{*}, \rho^{*}$ e $g^{*}$ são, respectivamente, as razões entre o comprimento, a densidade e a aceleração da gravidade do modelo e da natureza.
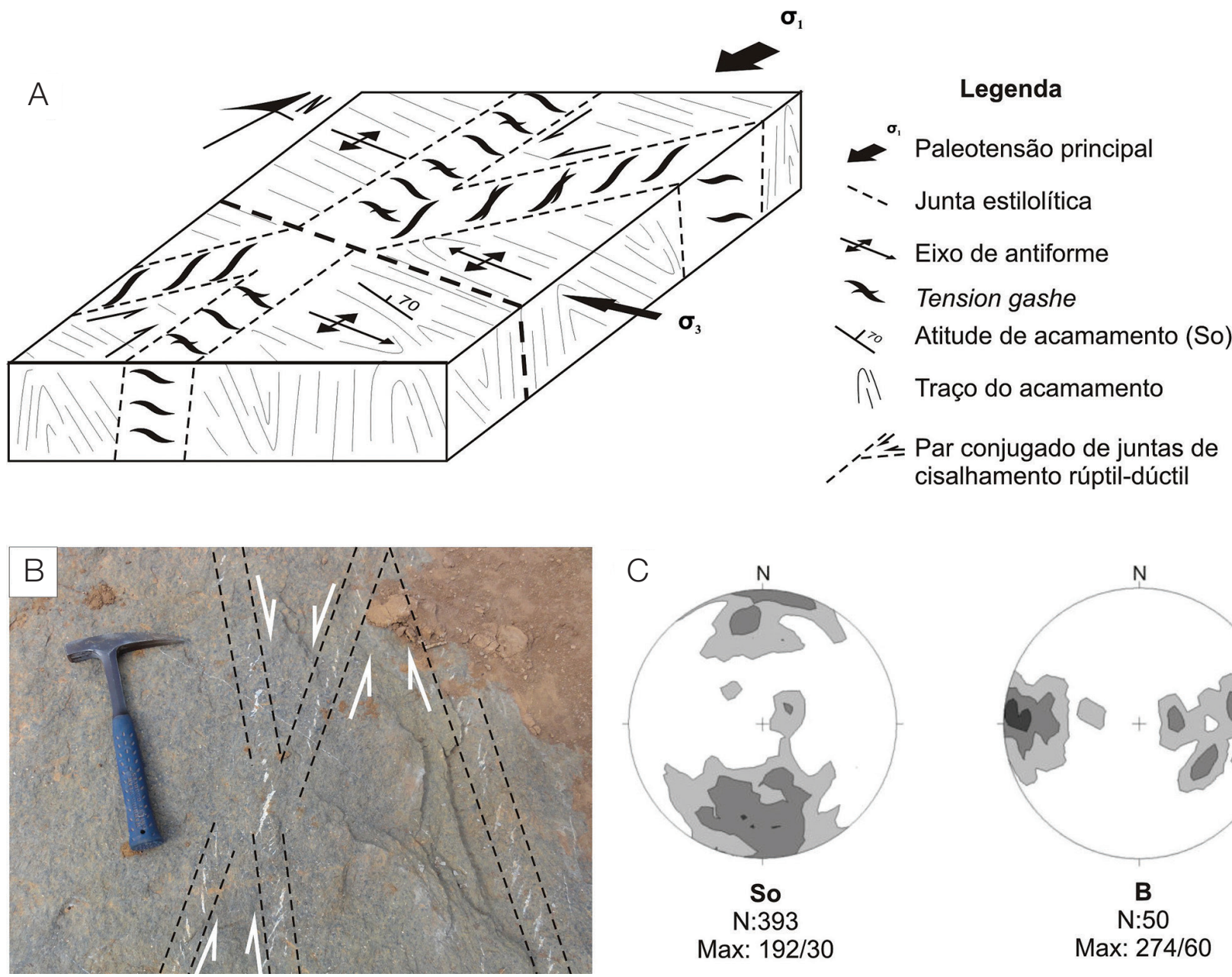

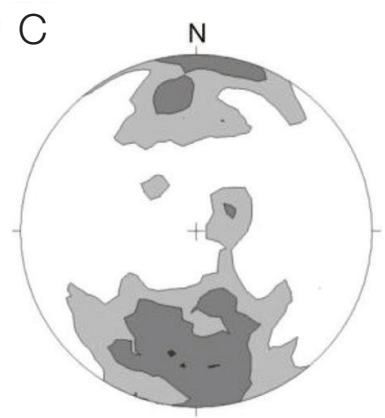

So

$\mathrm{N}: 393$

Max: $192 / 30$

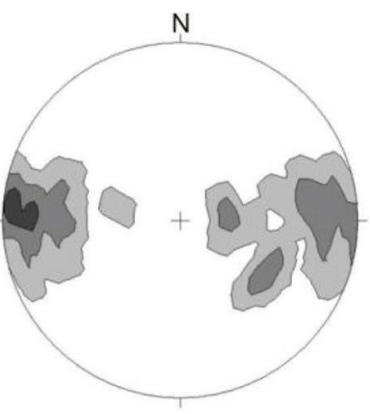

B

Max: $274 / 60$

Figura 5. (A) Diagrama mostrando a disposição geral das principais estruturas tectônicas observadas em carbonatos da Formação Salitre nas proximidades da cidade de Irecê (BA), porção central do sinclinal homônimo. (B) Fraturas de cisalhamento e tension gashes em trombólitos da Formação Salitre, norte do Município de Irecê (BA). Martelo apontando para norte. (C) Diagramas de polos do acamamento ("So") e de eixos de dobra ("B") relacionados à principal geração de estruturas tectônicas observadas no setor central da Bacia de Irecê. 

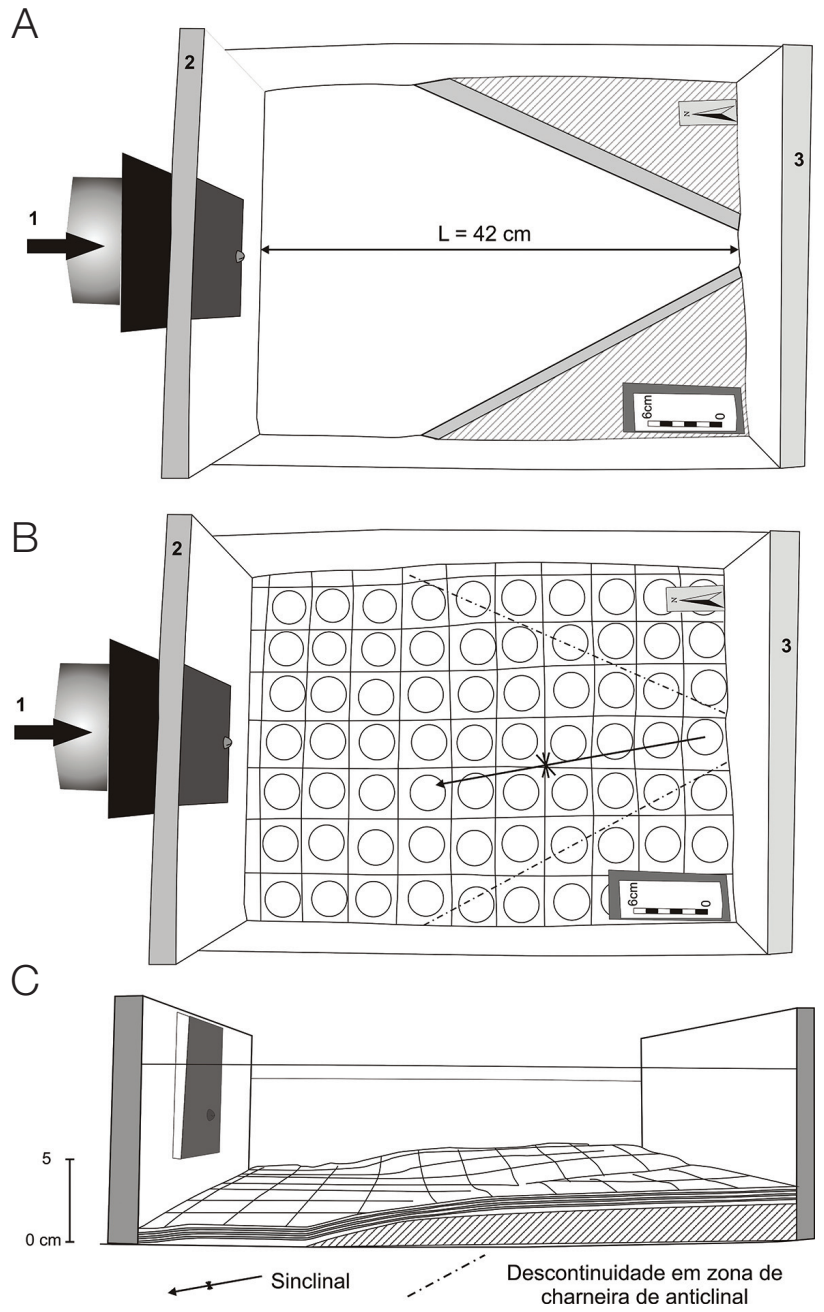

1: sentido da compressão; 2: placa móvel; 3: anteparo fixo. A malha quadrada e os círculos foram desenhados na superfície do experimento como marcadores da deformação.

Figura 6. Esquema mostrando a caixa de acrílico e a montagem do experimento. (A) Base da caixa. (B) e (C) Modelo analógico após acomodação da camada de areia + silicone sobre base irregular da caixa mostrada em (A) e desenvolvimento de uma estrutura sinclinal, comparável ao Sinclinal de Irecê.

A aplicação dos parâmetros da Tabela 1 na Equação 1 fornece um valor teórico de $\sigma^{*}$ de aproximadamente $26 \mathrm{~Pa}$. Uma vez que tal valor encontra-se na mesma ordem de grandeza do valor experimental apresentado para areia por Gomes et al. (2009, 2010) e Gomes e Caldeira (2011), considera-se que o modelo adotado satisfaz os critérios de similaridade dinâmica.

\section{Procedimentos experimentais}

Inicialmente, para simular o desenvolvimento do Sistema de Dobramentos e Empurrões da Chapada Diamantina, a areia foi disposta fora da caixa de experimentos segundo camadas horizontais de espessura milimétrica e sobre uma fina camada de silicone. Posteriormente, esse pacote foi introduzido em uma caixa de acrílico com a base irregular, conforme mostrado na Figura 7A. Sendo assim, foi gerada uma estrutura sinclinal (comparável ao Sinclinal de Irecê), ladeada por antiformes de proporções e orientação similar. Em seguida, com base no modelo geológico, foi aplicada uma tensão orientada levemente oblíqua ao eixo do sinclinal, o que permitiu um transporte tectônico aproximadamente segundo sua zona axial e uma deformação total em torno de $34 \%$ (Figura 7). A malha quadrada e os círculos previamente desenhados sobre a superfície do experimento permitiram observar e quantificar a deformação ao longo do ensaio (Figuras 7 e 8 ).

\section{RESULTADOS}

No experimento, foi desenvolvido um cinturão de falhas e dobras, confinado ao longo da estrutura sinclinal inicial e articulado em descolamento na base do pacote sedimentar, diretamente sobre a camada de silicone (Figura 8). Em planta, as estruturas geradas mostraram-se na forma de traços curvilíneos, definindo uma saliência com concavidade voltada para a placa móvel (hinterland) e limitada lateralmente por um par de falhas direcionais.

A propagação da deformação deu-se em duas etapas distintas (Figuras 7 e 8). Na primeira, falhas de empurrão frontais e retilíneas começaram a se desenvolver próximo à placa móvel com a propagação sistemática em direção ao antepaís. Em torno de 14\% de deformação, começaram a se nuclear as estruturas com componente direcional nas bordas do sinclinal. Após esse momento, na segunda etapa, as falhas de empurrão frontais voltaram a se desenvolver, concomitantemente à evolução das falhas direcionais laterais. Nessa etapa, as estruturas retilíneas mais antigas foram levemente rotacionadas e as estruturas mais novas foram nucleadas com o formato curvo, em função da influência das falhas de borda e da geometria do sinclinal confinante.

As falhas de empurrão nuclearam-se com ângulo entre $30^{\circ}$ e $35^{\circ}$, sendo posteriormente rotacionadas com o desenvolvimento das falhas mais jovens no antepaís. Ao final do experimento, as estruturas mais antigas (mais próximas ao hinterland) chegam a exibir ângulos de até $50^{\circ}$, em parte, influenciadas pela proximidade da placa móvel rígida. No modelo analógico, essas falhas de empurrão ocorrem localmente relacionadas a grandes depressões antiformais de orientação similar. No ápice da saliência, localizado na zona axial do sinclinal inicial, desenvolveu-se uma falha antitética tardia, isto é, um retroempurrão, que, juntamente com o empurrão frontal, definem uma estrutura do tipo рор-ир (Figura 8). 
Tabela 1. Parâmetros de escala adotados no modelo analógico.

\begin{tabular}{lccc}
\hline Parâmetro & Modelo & Natureza & Razão modelo/natureza \\
\hline Comprimento $(\mathrm{L})$ & $0,42 \mathrm{~m}$ & $158 \times 10^{3} \mathrm{~m}$ & $\mathrm{~L}^{*}=2,66 \times 10^{-6}$ \\
Gravidade $(\mathrm{g})$ & $9,81 \mathrm{~m} / \mathrm{s}^{2}$ & $9,81 \mathrm{~m} / \mathrm{s}^{2}$ & $\mathrm{~g}^{\star}=1$ \\
Densidade $(\mathrm{d})^{(\mathrm{a})}$ & $1,2-1,4 \mathrm{~kg} / \mathrm{m}^{3}$ & $2,4-2,8 \mathrm{~kg} / \mathrm{m}^{3}$ & $\rho^{*} \sim 0,5$ \\
Viscosidade $(\mu)$ & $10^{4} \mathrm{~Pa} \cdot \mathrm{s}^{*}$ & $10^{17}-10^{19} \mathrm{~Pa} \cdot \mathrm{s}^{(\mathrm{b})(\mathrm{c}) \star \star}$ & $\mu^{\star}=10^{13}-10^{15}$ \\
Taxa de deformação & $8,4 \times 10^{-6} \mathrm{~m} / \mathrm{s}(3 \mathrm{~cm} / \mathrm{h})$ & $3,2 \times 10^{-10} \mathrm{~m} / \mathrm{s}(1 \mathrm{~cm} / \mathrm{ano})^{(\mathrm{b})}$ & $\varepsilon^{\star}=2,63 \times 10^{4}$ \\
Tensão coesiva $(\sigma)$ & $60 \mathrm{~Pa}^{(\mathrm{a})}$ & $2 \times 10^{7} \mathrm{~Pa}^{(\mathrm{d})}$ & $\sigma^{\star}=<10^{-6}$ \\
\hline
\end{tabular}

(a)Gomes et al. (2009, 2010); (b)Pichot e Nalpas (2009); (c)Van Keken et al. (1993); (d)Handin (1966).

*Silicone; ${ }^{*}$ Valores considerados para litologias de comportamento dúctil, como folhelhos, argilitos, margas e sal.

A falha de empurrão com componente direcional destral, desenvolvida na porção oeste da saliência, tornouse mais longa do que a respectiva falha com componente sinistral da porção leste. $\mathrm{O}$ fato não se aplica às feições observadas na Bacia de Irecê e, no experimento, resultou da existência de pequenas fraturas axiais formadas durante a colocação das camadas de areia na caixa de acrílico (Figura 7A). Apesar disso, ambas exibem uma evolução similar em termos relativos (Figura 7F) e foram responsáveis pela extrusão lateral de todo o pacote para fora do sinforme confinante.

Em direção à placa fixa da caixa, o cinturão perde gradativamente sua expressividade. Nessa área, é observado apenas o sinclinal herdado, cujo eixo exibe leve caimento para a placa móvel (Figura 8).

\section{A EVOLUÇÃO DO CINTURÃO EPIDÉRMICO DE ANTEPAÍS DA BACIA DE IRECÊ E O MODELO TECTÔNICO ANALÓGICO}

Os resultados obtidos no experimento e os mapas geológicos (Figuras 1, 3, 7, 8) mostram grande correspondência, especialmente no que tange à curvatura do cinturão e às principais estruturas associadas (Figura 9). Em ambos os casos, observa-se uma curva com concavidade voltada para o hinterland, confinada no interior de uma grande calha sinclinal e composta por um conjunto de dobras e falhas vergentes para a região do antepaís. Lateralmente, a saliência é acomodada através de falhas de empurrão com componente direcional.

O desenvolvimento de cinturões epidérmicos já foi objeto de estudo de diversos autores, que apontam a íntima relação entre sua arquitetura, as características friccionais do descolamento, a espessura do pacote sedimentar, a geometria do substrato etc.

Por meio de modelos físico-analógicos, Huiqi et al. (1992) e Ribeiro (2001) demonstram que, quando desenvolvidos sobre descolamentos de menor coeficiente de atrito, cinturões epidérmicos tendem a desenvolver um menor número de falhas, ao passo que se propagam por maiores distâncias e exibem topografias menos acentuadas. Por outro lado, quando desenvolvidos sobre substrato com maior coeficiente de atrito, tendem a configurar cinturões curtos, dominados por falhas e topograficamente mais expressivos.

Ao analisar a geometria em planta de faixas dobradas utilizando modelos físico-analógicos, Macedo e Marshak (1999) e Marshak (2004) concluem que cinturões não rotacionais são fortemente influenciados por fatores como a geometria do substrato, as características reológicas do pacote estratigráfico deformado e suas variações de espessura, a existência de endentantes e obstáculos no antepaís, bem como mudanças regionais nas características do descolamento basal. Dessa forma, cinturões epidérmicos desenvolvidos sobre substratos curvos comumente se manifestam em superfície na forma de grandes curvas antitaxiais, cuja culminação localiza-se aproximadamente na zona de maior profundidade do descolamento. As geometrias podem se tornar cada vez mais complexas quando o cinturão interage com obstáculos no antepaís ou blocos rígidos endentantes no hinterland. Quando o descolamento é controlado por unidades estratigráficas de comportamento reológico dúctil, a distribuição das mesmas pode facilitar localmente a propagação do cinturão e, portanto, refletir em sua geometria em planta.

Levando em conta as similaridades observadas entre o modelo geológico e o modelo analógico, podem ser tecidas as seguintes considerações sobre o desenvolvimento do cinturão epidérmico de antepaís da Bacia de Irecê.

O cinturão desenvolveu-se sobre descolamento de baixo coeficiente de atrito, o que favoreceu sua propagação sinclinal adentro. Enquanto no modelo analógico esse descolamento é condicionado pela fina camada de silicone, no modelo geológico o mesmo parece ser consequência do contraste reológico entre os depósitos carbonáticos da porção superior do Grupo Una e as sucessões siliciclásticas inferiores. A existência de importantes ocorrências de 

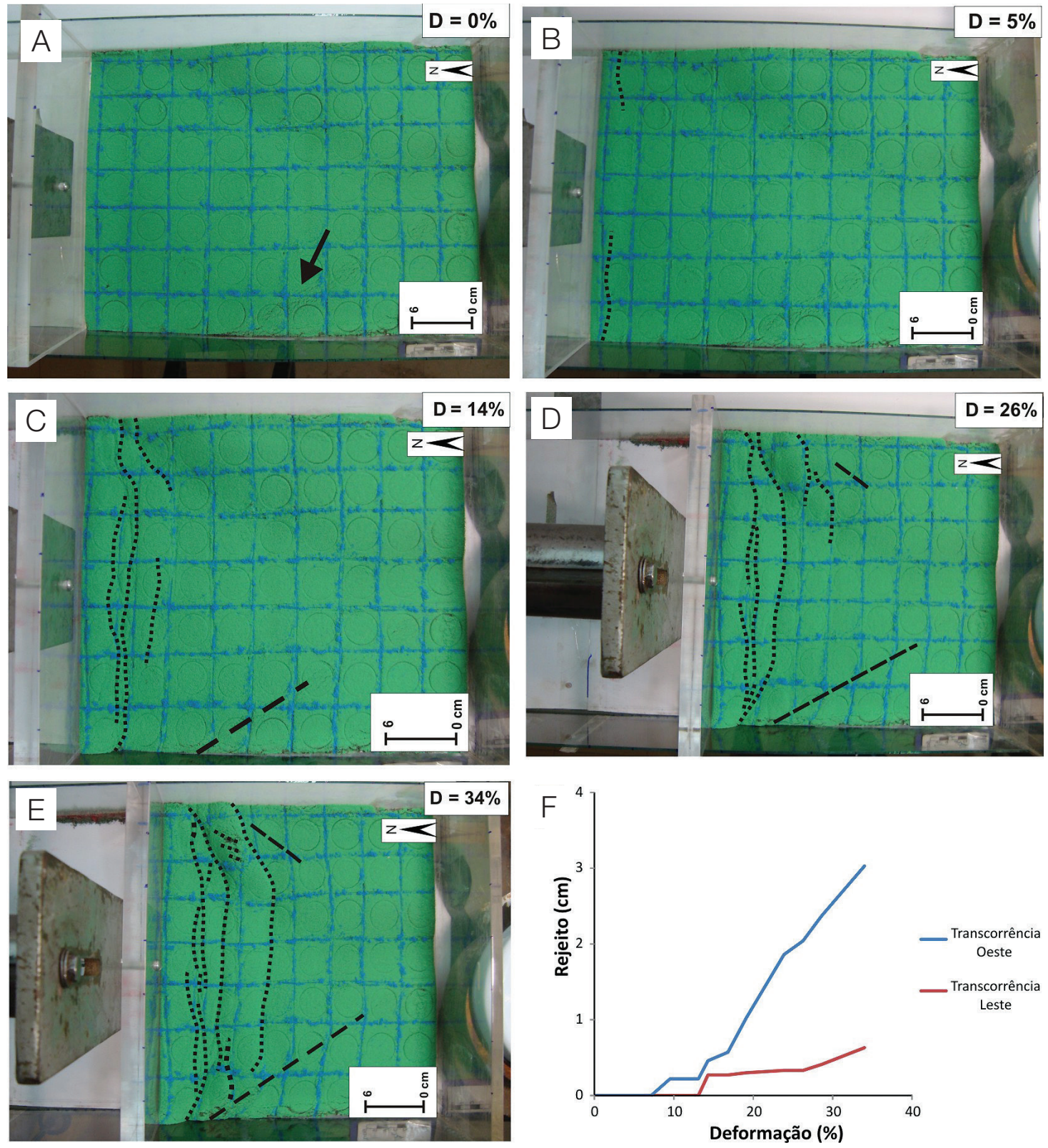

D: deformação (encurtamento).

Figura 7. (A) Configuração do experimento antes da deformação. A seta indica a descontinuidade formada na zona axial de antiforme gerado durante a acomodação das camadas de areia sobre a base irregular da caixa. (B), (C), (D) e (E) Etapas de deformação durante o experimento. Linhas pontilhadas e tracejadas correspondem aos principais traços estruturais observados em planta. Notar o desenvolvimento de zonas de $(F)$ Gráfico do rejeito $(\mathrm{cm})$ versus a deformação $(\%)$ relativos às falhas transcorrentes durante o experimento. O desenvolvimento absoluto mais acentuado da transcorrência oeste, quando comparada à transcorrência leste, se deve à prévia existência de uma descontinuidade no pacote arenoso, como mostrado em (A).

sulfato de bário ao longo da borda leste da bacia (Figura 1; Souza et al., 1993), onde aflora o descolamento basal, sugere ainda a influência de sucessões evaporíticas (?) no controle dessa feição, o que implicaria em um coeficiente de atrito ainda mais baixo para o detachment.

A propagação geral das estruturas ocorreu em direção ao antepaís, sendo acomodada lateralmente por falhas direcionais com componente oblíquo. A curvatura do cinturão teria sido resultado tanto da leve rotação tardia das estruturas nucleadas nos estágios iniciais quanto da interação com as bordas do sinclinal confinante após o desenvolvimento das falhas direcionais laterais. Aparentemente, a curvatura do substrato também exerceu importante papel no desenvolvimento do cinturão, onde o ápice da saliência localiza-se 

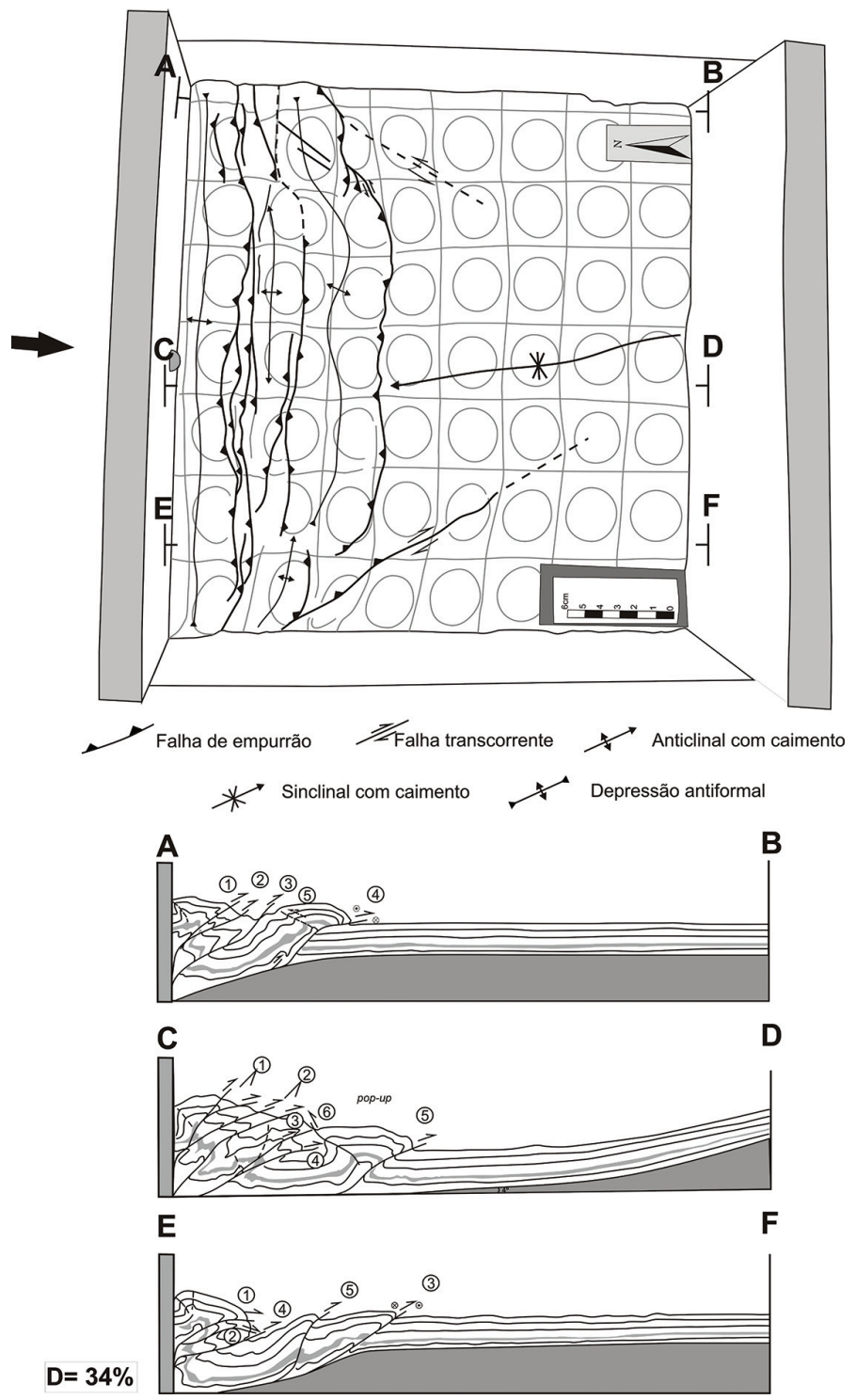

Figura 8. Desenho e interpretação do experimento ao final da deformação (D) de 34\%. Os perfis AB, CD e EF mostram as principais estruturas desenvolvidas nas porções leste, central e oeste do experimento, respectivamente, e os números, a idade relativa das falhas em cada um dos perfis.

ao longo da zona axial da Bacia de Irecê, como sugerido por Ribeiro (2001). Apesar de não descrito no modelo geológico (Figuras 1 e 3), nesta zona desenvolveu-se uma estrutura do tipo pop-up, feição comumente observada na porção externa de cinturões de antepaís (Decelles e Giles, 1996).

No modelo analógico, não foi notado nenhum tipo de estrutura de interferência resultante da interação entre pacote descolado e as bordas do sinclinal confinante. A única peculiaridade relacionada à influência dos limbos do Sinclinal de Irecê refere-se à cronologia de geração das falhas. Como observado no experimento, a nucleação das falhas de empurrão é entremeada pelo desenvolvimento das falhas laterais com componente direcional, que, posteriormente, passam a exercer alguma influência sobre sua curvatura.

Uma feição notável desenvolvida no modelo analógico são as depressões antiformais (Figura 8). Tais elementos não são destacados nos mapas estruturais regionais da Bacia de Irecê; entretanto, representam a consequência direta da superposição das duas fases de deformação observadas no modelo analógico. Atualmente, os elementos de superposição tectônica mais bem descritos na Bacia de Irecê restringem-se às estruturas de interferência em sua porção interna (e.g., Lagoeiro, 1990; Souza et al., 1993), que geralmente possuem dimensões de afloramento. 

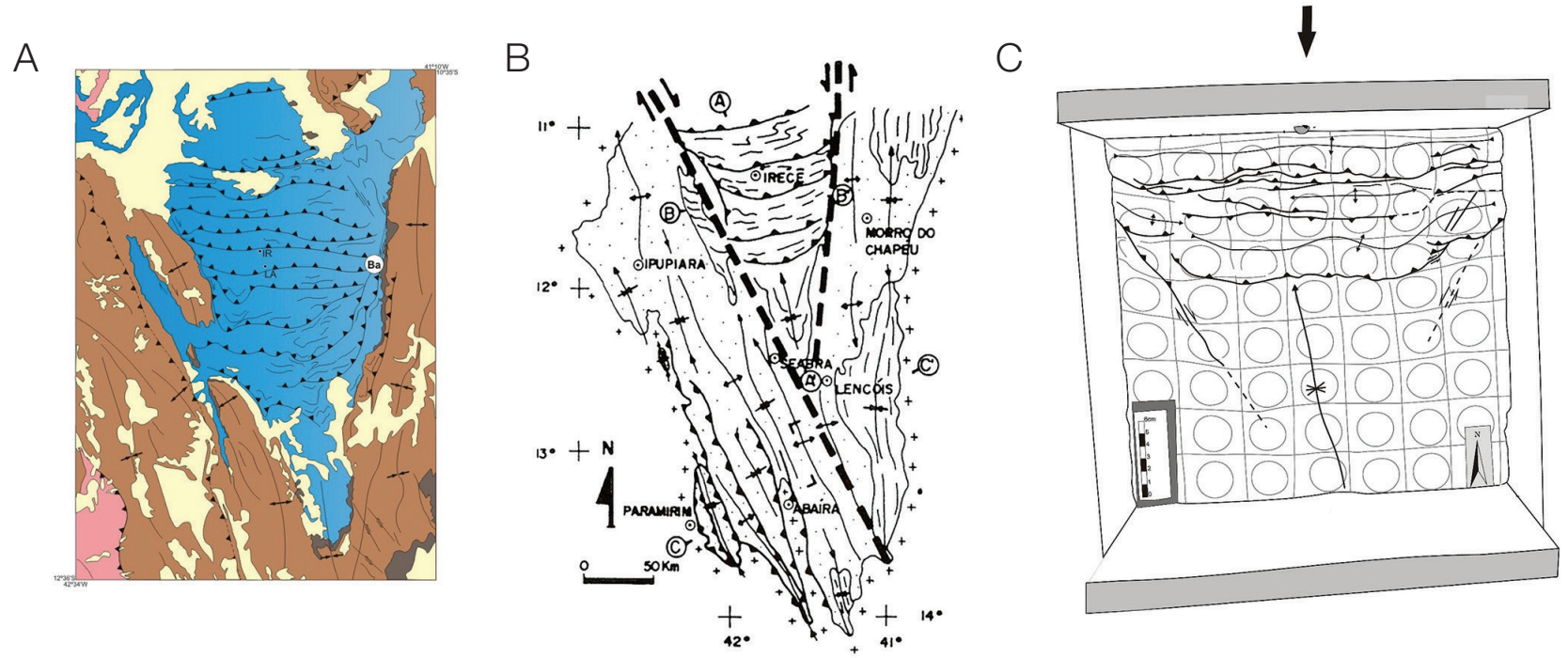

Fonte: A: modificado de Dalton de Souza et al. (2003), Lagoeiro (1990) e Danderfer Filho (1990) e Kuchenbecker et al. (2011); B: Danderfer Filho et al. (1993). Legendas de $(A)$ e $(C)$ nas Figuras 1 e 8, respectivamente.

Figura 9. Comparação entre mapas geológicos regionais (A e B) da Bacia de Irecê e os resultados obtidos no experimento (C).

O sinclinal de eixo NNW-SSE pendente para NNW na extremidade sul da Bacia de Irecê (Lagoeiro, 1990; Dalton de Souza et al., 2003) corresponde a uma estrutura herdada do Sistema de Dobras e Empurrões da Chapada Diamantina, intensificada passivamente pelo desenvolvimento do cinturão de antepaís.

\section{CONSIDERAÇÕES FINAIS}

Conforme diversos autores (e.g., Danderfer Filho, 1990; Lagoeiro, 1990; Danderfer Filho et al., 1993; Alkmim, 2004), os dois sistemas deformacionais observados no setor oriental do Aulacógeno do Paramirim correspondem à expressão intracratônica das sucessivas orogenias que afetaram as margens do Cráton do São Francisco ao fim do Pré-Cambriano.

Durante o período Ediacarano, o fechamento do Orógeno Araçuaí (Pedrosa-Soares et al., 2007) teria culminado na estruturação do Sistema de Dobramentos e Empurrões da Chapada Diamantina. Esse cinturão embrionário resultou de um encurtamento geral WSWENE, responsável pela estruturação principal observada no Aulacógeno do Paramirim (Cruz e Alkmim, 2006). Ao longo da área de estudo, essa fase tectônica manifesta-se através de um sistema de dobras regionais com eixos orientados preferencialmente segundo NNW-ESE, que envolvem tanto os depósitos do Supergrupo Espinhaço quanto as sucessões neoproterozoicas do Grupo Una. Dentre as principais estruturas geradas nessa etapa, destaca-se a Bacia de Irecê (s.l.), que corresponde a uma grande calha sinclinal com eixo NNW-SSE pendente para NNW e onde ocorrem as principais exposições neoproterozoicas da porção norte do Cráton do São Francisco.

Considerando-se os dados geocronológicos sintetizados por Pedrosa-Soares et al. (2007) e a análise estrutural apresentada por Cruz e Alkmim (2006), essa fase tectônica deu-se em torno de 560 - $580 \mathrm{Ma}$. Tal período marca a etapa sin-colisional do Orógeno Araçuaí e caracteriza-se pelo metamorfismo e deformação regionais, sendo acompanhada pela intensa granitogênese do tipo $\mathrm{S}$ em sua porção sul.

O cinturão epidérmico de antepaís da Bacia de Irecê corresponde a uma grande feição curva confinada ao longo do sinclinal homônimo e tem sua formação atribuída ao fechamento das faixas marginais do setor norte do Cráton do São Francisco (Danderfer Filho, 1990; Lagoeiro, 1990; Alkmim, 2004). Seu desenvolvimento foi condicionado por um vetor tectônico $(\sigma 1)$ de direção aproximada N-S, responsável pela nucleação, predominantemente, de sistemas de dobras e falhas E-W, pares conjugados de fraturas NE-SW e NW-SE com tension gashes associados, bem como juntas estilolíticas. Ao longo das bordas da bacia, o cinturão é acomodado através de sistemas de falhas direcionais responsáveis pela rotação geral das estruturas (Lagoeiro, 1990). Em direção à porção sul da Bacia de Irecê, o cinturão perde gradativamente sua expressividade, sendo que, nesse setor, ocorrem apenas as estruturas geradas previamente durante o desenvolvimento do Sistema de Dobras e Empurrões da Chapada Diamantina.

O modelo físico-analógico em caixa de areia elaborado simulou com sucesso o desenvolvimento do cinturão epidérmico de antepaís da Bacia de Irecê e sugere que o 
mesmo propagou-se em direção ao antepaís, sendo sua curvatura em planta resultante da interação com as bordas do sinclinal e da própria curvatura do substrato. Tal propagação deu-se através de um descolamento com baixo coeficiente de atrito, provavelmente condicionado pelo contraste reológico entre as unidades carbonáticas do Grupo Una e o substrato siliciclástico composto principalmente pelas rochas siliciclásticas do Supergrupo Espinhaço.

No modelo, as depressões antiformais de caráter regional representam estruturas resultantes da superposição das duas fases de deformação experimentadas pelas sucessões análogas. Estruturas de interferência são frequentemente descritas ao longo da Bacia de Irecê; entretanto, correspondem, entre outras, a feições do tipo "domos e bacias", geralmente em escala mesoscópica (Souza et al., 1993). Com o experimento, não foi possível associar qualquer dessas feições com as interações entre o cinturão e as bordas do sinclinal confinante, como proposto por Fragoso et al. (2008) e Kuchenbecker et al. (2011). Aparentemente, para tal, seria necessária transmissão de esforços mais efetiva pelo descolamento ao longo do sistema.

Apesar de comumente atrelado ao fechamento das faixas marginais ao norte do Cráton do São Francisco (Danderfer, 1990; Lagoeiro, 1990; Alkmim, 2004; Cruz e Alkmim, 2006), o desenvolvimento do cinturão epidérmico de antepaís da Bacia de Irecê ainda carece de amarrações geocronológicas mais precisas.

Considerando-se a idade aproximada de geração do Sinclinal de Irecê e estruturas associadas, é possível supor que o cinturão desenvolveu-se após $560-580 \mathrm{Ma}$ (Pedrosa-Soares et al., 2007). Ao sintetizar as escassas e pouco precisas idades geocronológicas disponíveis ao longo das faixas Rio Preto e Riacho do Pontal (Figura 1), Uhlein et al. (2011) indicam importante metamorfismo e deformação no setor norte do Cráton do São Francisco entre 668 e $540 \mathrm{Ma}$. Sendo assim, é possível estimar o desenvolvimento do cinturão epidérmico de antepaís da Bacia de Irecê entre 580 e $540 \mathrm{Ma}$. Desta forma, ele seria posterior ao desenvolvimento do Sistema de Dobras e Empurrões da Chapada Diamantina e concomitante à deformação das faixas marginais a norte do cráton, especialmente ao sistema de nappes da porção externa da Faixa Riacho do Pontal (Uhlein et al., 2011).

\section{AGRADECIMENTOS}

Os autores dedicam sinceros agradecimentos à Petra Energia S.A. e à PETROBRAS, pelo apoio técnico e logístico, e à Fundação de Amparo à Pesquisa do Estado de Minas Gerais (FAPEMIG) (CRA-APQ-01672-11) pelo suporte financeiro.

\section{REFERÊNCIAS}

Alkmim, F. F. (2004). O que faz de um cráton um cráton? O Cráton do São Francisco e as revelações almeidianas ao delimitá-lo. In: V. Mantesso-Neto, A. Bartorelli, C. D. R. Carneiro, B. B. Brito-Neves (Orgs.), Geologia do Continente Sul Americano: Evolução da obra de Fernando Flávio Marques de Almeida (17-35). São Paulo: Beca.

Alkmim, F. F., Brito Neves, B. B., Castro Alves, J. A. (1993). Arcabouço Tectônico do Cráton do São Francisco: uma revisão. In: J. M. L. Dominguez, A. Misi (Eds.), $O$ Cráton do São Francisco (v. 1, 45-62). Salvador: SBG/ $\mathrm{SGM} / \mathrm{CNPq}$.

Barbosa, J. S. F., Dominguez, J. M. L. (1996). Geologia da Bahia: texto explicativo para o mapa geológico ao milionésimo. Escala 1: 1.000.000. Salvador: Secretaria da Indústria, Comércio e Mineração. Superintendência de Geologia e Recursos Minerais.

Bomfim, L. F. C., Rocha, A. J. D., Pedreira, A. J., MoraisFilho, J. C., Guimarães, J. T., Tesch, N. A. (1985). Projeto Bacia de Irecê, Relatório Final. Salvador: CPRM.

Brito Neves, B. B. (1967). Geologia das Folhas de Upamirim e Morro do Chapéu, Relatório 17. Recife: CONESP.

Cruz, S. C. P., Alkmim, F. F. (2006). The tectonic interaction between the Paramirim Aulacogen and the Araçuaí belt, São Francisco craton region, Eastern Brazil. Anais da Academia Brasileira de Ciências, 78(1), 151-173.

Dalton de Souza, J., Kosin, M., Melo, R. C., Santos, R. A., Teixeira, L. R., Sampaio, A. R., Guimarães, J. T., Vieira Bento, R., Borges, V. P., Martins, A. A. M., Arcanjo, J. B., Loureiro, H. S. C., Angelim, L. A. A. (2003). Mapa geológico do Estado da Bahia. Escala 1:1.000.000. Salvador: CPRM.

Danderfer Filho, A. (1990). Análise Estrutural Descritiva e Cinemática do Supergrupo Espinhaço na Região da Chapada Diamantina, Bahia, Brasil. Dissertação (Mestrado). Ouro Preto: Escola de Minas, Departamento de Geologia - UFOP.

Danderfer Filho, A., Lagoeiro, L. E., Alkmim, F. F. (1993). O Sistema de dobramentos e empurrões da Chapada Diamantina (BA): Registro da inversão do Aulacógeno do Espinhaço no decorrer do Evento Brasiliano. In: J. M. L Dominguez, A. Misi (Eds.), O Cráton do São Francisco (v.1, 197-199). Salvador: SBG/SGM/CNPq. 
Decelles, P. G., Giles, K. A. (1996). Foreland basin systems. Basin Research, 8, 105-123.

Dominguez, J. M. L. (1993). As Coberturas do Cráton do São Francisco: Uma Abordagem do Ponto de Vista da Análise das Bacias. In: J. M. L. Dominguez, A. Misi (Eds.), O Cráton do São Francisco (v. 1, 137-159). Salvador: SBG/SGM/CNPq.

Figueiredo, F. T. (2008). Fácies sedimentares $e$ proveniência da Formação Bebedouro, Neoproterozóico (BA). Dissertação (Mestrado). São Paulo: Instituto de Geociências - USP.

Fragoso, D. G. C., Reis, H. L. S., Kuchenbecker, M. (2008). Mapeamento Geológico da região de Irecê-Lapão (BA): Registros de uma rampa carbonática neoproterozóica. Monografia (Graduação). Belo Horizonte: Instituto de Geociências - UFMG.

Gomes, C. J. S., Caldeira, J. N. M. (2011). As propriedades friccionais de areias de quartzo (natural e colorida): medidas efetuadas em experimentos físicoanalógicos e em um ring-shear tester. Revista Escola de Minas, 64(3), 289-298.

Gomes, C. J. S., Danderfer Filho, A., Hercos, C. M. (2010). Deformação da cobertura com embasamento envolvido em caixas de areia: estudo de caso da região da Serra da Água Fria (MG), Bacia do São Francisco. Revista Brasileira de Geociências, 40(4), 561-572.

Gomes, C. J. S., Silva, F. C. A., Rosenau, M., Klinkmüller, M. (2009). As propriedades mecânicas da areia de quartzo medidas em um Ring-Shear Tester. XXII Simpósio Nacional de Estudos Tectônicos, VI International Symposium on Tectonics, 47, Ouro Preto: SBG.

Guimarães, J. T. (1996). A Formação Bebedouro no Estado da Bahia: Faciologia, estratigrafia e ambientes de sedimentação. Dissertação (Mestrado). Salvador: Instituto de Geociências - UFBA.

Handin, J. (1966). Strength and ductility. In: S. P. Clark, Jr. (Ed.), Handbook of Physical Constants (223-289, Memoir 97). Boulder: Geological Society of America.

Hubbert, M. K. (1937). Theory of scale models as applied to the study of geologic structures. Geological Society of America Bulletin, 48, 1459-1520.
Huiqi, L., McClay, K. R., Powell, D. (1992). Physical models of thrust wedges. In: K. R. McClay (Ed.), Thrust Tectonics (71-81). London: Chapman \& Hall.

Inda, H. A. V., Barbosa, J. F. (1978). Texto explicativo para o Mapa Geológico do Estado da Bahia. Escala 1:1.000.000. Salvador: CPM-SME BA/CBPM.

Kuchenbecker, M., Reis, H. L. S., Fragoso, D. G. C. (2011). Caracterização estrutural e considerações sobre a evolução tectônica da Formação Salitre na porção central da Bacia de Irecê, norte do Cráton do São Francisco (BA). Geonomos, 19(2), 42-49.

Lagoeiro, L. E. (1990). Estudo da deformação nas seqüências carbonáticas do Grupo Una, na região de Irecê, Bahia. Dissertação (Mestrado). Ouro Preto: Escola de Minas, Departamento de Geologia - UFOP.

Lujan, M., Storti, F., Balanyá, J. C., Crespo-Blanc, A., Rossetti, F. (2003). Role of décollement material with different rheological properties in the structure of the Aljibe thrust imbricate (Flysh Trough, Gibraltar Arc): an analog modeling approach. Journal of Structural Geology, 25, 867-881.

Macedo, J., Marshak, S. (1999). Controls on the geometry of fold-thrust belt salients. Geological Society of America Bulletin, 111(12), 1808-1822.

Marshak, S. (2004). Salients, recesses, arcs, oroclines and syntaxes - A review of ideas concerning the formation of map-views curves in fold-thrust belts. In: K. R. McClay (Ed.), Thrust tectonics and hydrocarbon systems (131-156, Memoir 82). Boulder: AAPG.

Pedreira,A.J.(1994). OSupergrupo Espinhaçona Chapada Diamantina centro-oriental, Bahia: Sedimentologia, Estratigrafia e Tectônica. Tese (Doutorado). São Paulo: Instituto de Geociências - USP.

Pedreira, A. J., De Waele, B. (2008). Contemporaneous evolution of the Paleoproterozoic-Mesoproterozoic sedimentar basins of the São Francisco-Congo Craton. In: R. J. Pankhurst, R. A. J. Trow, B. B. Brito Neves, M. J. De Wit (Eds.), West Gondwana: Pre-Cenozoic Correlations Across the South Atlantic Region (Special Publication 294, 33-48). London: Geological Society of London.

Pedreira, A. J., Rocha, A. J. D., Costa, I. V. G., Moraes Filho, J. C. (1987). Projeto Bacia de Irecê II, Relatório final. Salvador: CPRM. 
Pedrosa-Soares, A. C., Noce, C. M., Alkmim, F. F., Silva, L. C., Babinski, M., Cordani, U. G., Castañeda, C. (2007). Orógeno Araçuaí: síntese do conhecimento 30 anos após Almeida 1977. Geonomos, 15(1), 1-16.

Pichot, T., Nalpas, T. (2009). Influence of sinkynematic sedimentatios in a thrust system with two decollemènt levels: analogue modeling. Tectonophysics, 473, 466-475.

Ramberg, H. (1981). Gravity, Deformation, and the Earth's Crust (2a ed.). London: Academic Press.

Ribeiro, F. M. (2001). A geometria tridimensional de falhas de empurrão, investigada através de Modelagem Física Analógica. Tese (Doutorado). Ouro Preto: Escola de Minas, Departamento de Geologia - UFOP.

Rocha, G. M. F., Dominguez, J. M. L. (1993). As fases de deformação brasiliana atuantes nos Supergrupos
Espinhaço e São Francisco no estado da Bahia. In: J. M. L. Dominguez, A. Misi (Eds.), O Cráton do São Francisco (v. 1, 200-204). Salvador: SBG/SGM/CNPq.

Souza, S. L., Brito, P. C. R., Silva, R. W. S. (1993). Estratigrafia, Sedimentologia e Recursos Minerais da Formação Salitre na Bacia de Irecê, Bahia (Série Arquivos Abertos 2). Salvador: CBPM.

Uhlein, A., Caxito, F. A., Sanglard, J. C. D., Uhlein, G. J., Suckau, G. L. (2011). Estratigrafia e tectônica das faixas neoproterozoicas da porção norte do Cráton do São Francisco. Geonomos, 19(2), 8-31.

Van Keken, P. E., Spiers, C. J., Van Der Berg, A. P., Muyzert, E. J. (1993). The effective viscosity of rocksalt: implementation of steady-state creep laws in numerical models of salt diapirism. Tectonophysics, 225, 457-476. 